\title{
Whole Genome Amplification by T7-Based Linear Amplification of DNA (TLAD): II. Second-Strand Synthesis and In Vitro Transcription
}

\author{
Chih Long Liu, Bradley E. Bernstein, and Stuart L. Schreiber
}

This protocol was adapted from "DNA Linear Amplification," Chapter 7, in Whole Genome Amplification: Methods Express (eds. Hughes and Laskin), from the Methods Express series. Scion Publishing Ltd., Oxfordshire, UK, 2005.

\section{INTRODUCTION}

T7-based linear amplification of DNA (TLAD) uses a linear amplification approach based on in vitro transcription (IVT) of template DNA by RNA polymerase from the T7 phage. TLAD was designed primarily for use with the ChIP-chip method (whereby DNA recovered from chromatin immunoprecipitation [ChIP] of cell lysate is used for subsequent analysis on DNA microarrays) and requires nanogram quantities of dsDNA to generate microgram amounts of amplified RNA. Briefly, the strategy is to add a $3^{\prime}$ conserved end to the template dsDNA, using terminal deoxynucleotidyl transferase (TdT) tailing, which permits the addition of a T7 promoter sequence in the subsequent second-strand synthesis step, described here. At this stage, the strand-displacement activity of the Klenow fragment polymerase separates the two strands of the template DNA, after which the enzyme performs fill-in $5^{\prime} \rightarrow$ $3^{\prime}$ polymerization. Its $3^{\prime} \rightarrow 5^{\prime}$ exonuclease activity may also remove the $3^{\prime}$ overhanging poly(dT) tails, although the efficiency of this activity will vary based on the length of the poly(dT) tail. IVT can then use this newly appended T7 promoter. Because the T7-based IVT proceeds as an isothermal reaction, it linearly amplifies the template DNA, producing antisense RNA (aRNA) (i.e., each strand of RNA produced is antisense to the original template strand). Since both strands are amplified, this distinction is usually not important and is affected only by the location of the T7 promoter and poly $(A)$ tract on the aRNA.

\section{RELATED INFORMATION}

Information about ChIP-chip and an overview of the TLAD method (including suggested controls and interpretation of results) is provided in Whole Genome Amplification by T7-Based Linear Amplification of DNA (TLAD): Overview (Liu et al. 2008a). The articles Whole Genome Amplification by T7-Based Linear Amplification of DNA (TLAD): I. CIP Treatment of Samples and Tailing Reaction with Terminal Transferase (Liu et al. 2008b) and Whole Genome Amplification by T7-Based Linear Amplification of DNA (TLAD): III. Sample Purification (Liu et al. 2008c) detail Parts I and III, respectively, of the TLAD method. TLAD was originally described by Liu et al. (2003); a schematic of the method is shown in Figure 1.

\section{MATERIALS}

CAUTIONS AND RECIPES: Please see Appendices for appropriate handling of materials marked with $<!>$, and recipes for reagents marked with $<\mathbf{R}>$. 


\section{Reagents}

DNA polymerase I Klenow fragment (5000 units/mL) (New England Biolabs)

DNA template from Whole Genome Amplification by T7-Based Linear Amplification of DNA (TLAD): I. CIP Treatment of Samples and Tailing Reaction with Terminal Transferase (Liu et al. 2008a) [poly(dT)-tailed]

dNTP mix (5.0 mM) (Invitrogen)

This is a deoxynucleotide mixture containing $5 \mathrm{mM}$ each of dATP, dCTP, dTTP, and dUTP. Avoid subjecting the dNTP mix to more than three freeze-thaw cycles. Additional freeze-thaw cycles will further degrade the dNTPS and reduce the reaction yield.

$<$ R $>$ EDTA (0.5 M) (pH 8.0)

$\mathrm{H}_{2} \mathrm{O}$ (nuclease-free)

MinElute Reaction Cleanup kit (containing MinElute columns; Buffer ERC; Buffer PE; Buffer EB) (QIAGEN)

Add $95 \%$ or $100 \%$ RNase-free ethanol to Buffer PE before use; see manufacturer's protocol.

NEB Buffer 2 (New England Biolabs)

$<!>$ In early 2004, New England Biolabs switched the supplied buffer for the Klenow enzyme from EcoPol Buffer (10 mM Tris-HCl at pH 7.5; $5 \mathrm{mM} \mathrm{MgCl} ; 7.5 \mathrm{mM}$ DTT) to NEB Buffer 2. NEB Buffer 2 is typically supplied with the Klenow fragment enzyme and contains the following: $50 \mathrm{mM} \mathrm{NaCl} ; 10 \mathrm{mM}$ Tris- $\mathrm{HCl}(\mathrm{pH} 7.9) ; 10 \mathrm{mM}$ $\mathrm{MgCl}_{2} ; 1 \mathrm{mM}$ DTT. NEB Buffer 2 performs at least equivalently, if not better, than the EcoPol Buffer, which had to be pre-warmed to $37^{\circ} \mathrm{C}$ to dissolve any precipitated DTT.

Primer adapter: T7-A ${ }_{18}$ B (5'-GCATTAGCGGCCGCGAAATTAATACGACTCACTATAGGGAG(A) ${ }_{18}$ [B]-3') $(25 \mu \mathrm{M})$

$[B]$ stands for any base other than $A$; the primer thus consists of a mix of primers that end in $C, G$, or $T$. This primer adapter should be obtained by high-pressure liquid chromatography, polyacrylamide gel electrophoresis, or an equivalent purification method.

Sodium acetate (3 M, pH 5.0) (optional; see Step 6)

T7 Megascript Kit (containing $75 \mathrm{mM}$ each of ATP, CTP, GTP, and UTP nucleotide solutions; pTRI-Xef [0.5 mg/mL] control template [optional]; nuclease-free $\mathrm{H}_{2} \mathrm{O} ; 10 X$ reaction buffer; 10X enzyme mix [T7 RNA polymerase and a proprietary RNase inhibitor]) (Ambion)

If using a new kit, combine the NTP solutions into one tube, then aliquot back out into the four tubes. In the first three freeze-thaw cycles, yields drop 10\%-15\% after each cycle. If the NTPs go through more than three freeze-thaw cycles, each subsequent freeze-thaw cycle may additionally drop the yield by as much as $50 \%$.

Warm 10X reaction buffer to room temperature before use.

\section{Equipment}

Air incubator preset to $37^{\circ} \mathrm{C}$

Microcentrifuge

Thermal cycler

Tubes (0.2-mL thermal cycler-compatible, RNase-free)

$0.2 \mathrm{~mL}$-tubes are used to minimize vapor volume (Step 13).

Vacuum centrifuge

\section{METHOD}

RNA is produced at the end of this protocol; practice correct techniques to maintain an RNase-free environment.

\section{Second-Strand Synthesis with Klenow Fragment Polymerase}

1. Prepare the second-strand reaction mixture by combining:

$2.5 \mu \mathrm{L}$

$1 \mu \mathrm{L}$
10X NEB Buffer 2 ( $1 \mathrm{X}$ final concentration)

$5 \mathrm{mM}$ dNTP solution (200 $\mu \mathrm{M}$ final concentration) 


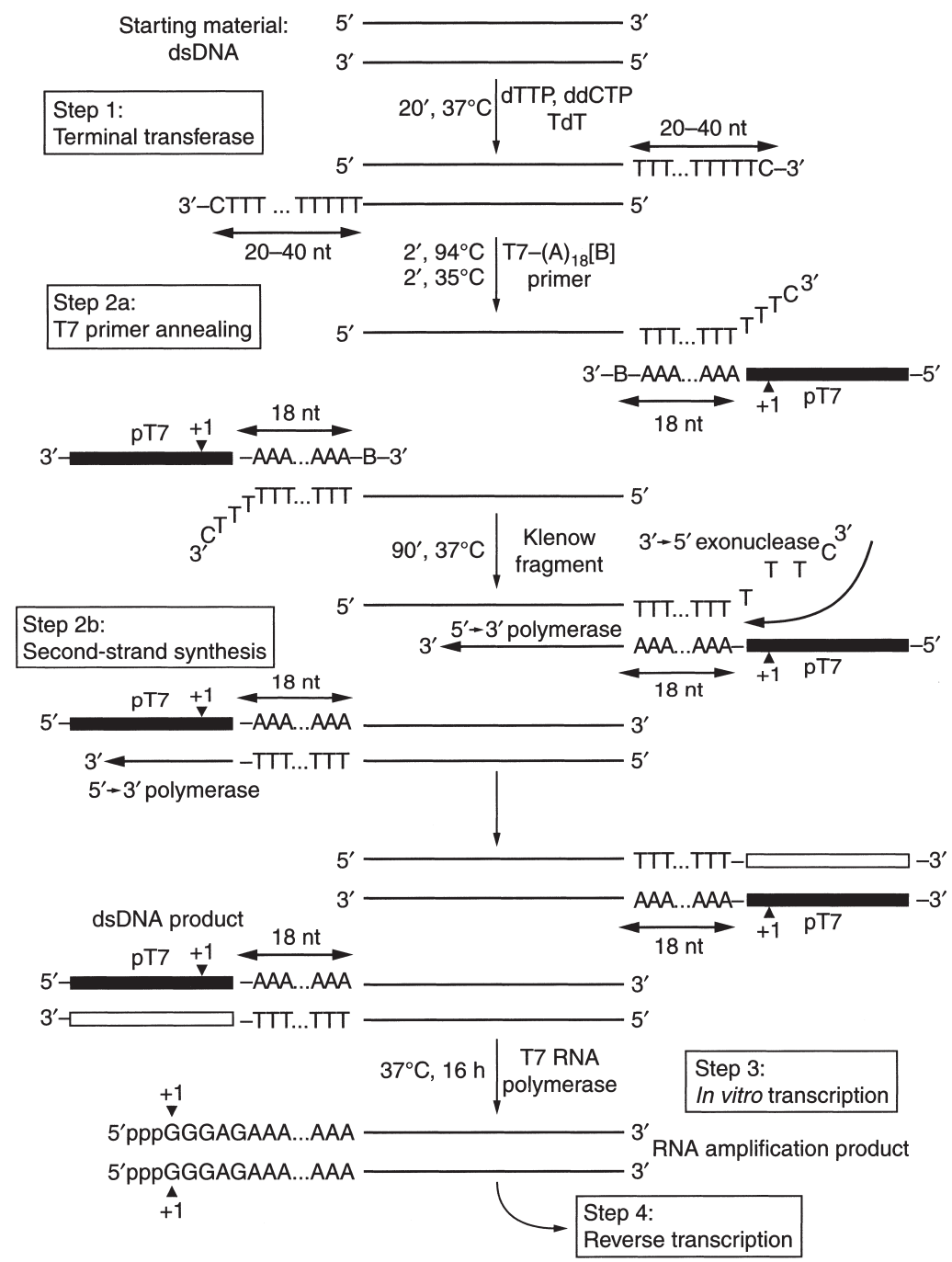

FIGURE 1. General strategy for the TLAD method. Starting with dsDNA template, TdT is used to add a poly(dT) tail to the $3^{\prime}$-ends of the template. This tail subsequently provides a conserved binding site for the annealing of T7 promoter (pT7)-poly(dA) primer adapters. Following subsequent second-strand synthesis using the large fragment of DNA polymerase I (Klenow fragment), one pair of dsDNA templates, with each pair member representing one of the two complementary strands of the dsDNA, is generated, with a T7 promoter at the $5^{\prime}$-end of the amplicon. In the subsequent IVT step, RNA is transcribed from this template in an isothermal reaction, producing an RNA amplification product consisting of both strands of the original dsDNA template in high microgram quantities. Note that each RNA strand will contain a short sequence from the T7 promoter and a poly $(\mathrm{A})$ tract, 5 ' relative to the amplicon. (Reprinted with permission from Liu et al. [2003].)

$0.3 \mu \mathrm{L}$
$20 \mu \mathrm{L}$

To $24 \mu \mathrm{L}$ final volume $(0.2 \mu \mathrm{L}) \quad$ Nuclease-free $\mathrm{H}_{2} \mathrm{O}$
$25 \mu \mathrm{M}$ T7- $\mathrm{A}_{18}$ B primer (300 nM final concentration)

Poly(dT)-tailed template DNA from Whole Genome Amplification by T7Based Linear Amplification of DNA (TLAD): I. CIP Treatment of Samples and Tailing Reaction with Terminal Transferase (Liu et al. 2008a)

These volumes correspond to a typical reaction volume of $25 \mu \mathrm{L}$, taking into account the $1 \mu \mathrm{L}$ of Klenow polymerase to be added in Step 3. The volume should be scaled up to $50 \mu \mathrm{L}$ if the tailing reaction in Step 9 of Whole Genome Amplification by T7-Based Linear Amplification of DNA (TLAD): I. CIP Treatment of Samples and Tailing Reaction with Terminal Transferase (Liu et al. 2008a) was scaled up to $20 \mu \mathrm{L}$. Refer to Table 1, which contains optimized primer amounts and recommended final reaction volumes for a given starting amount of DNA, for any necessary adjustments.

Avoid use of mineral oil, because trace amounts of mineral oil may interfere with the IVT reaction (Steps 11-13). 
Table 1. Second-strand synthesis with limiting primer amounts

\begin{tabular}{llllllll}
\hline DNA (ng) & $\begin{array}{l}\text { T7 primer } \\
(\mu \mathrm{L})^{\mathrm{a}}\end{array}$ & $\begin{array}{l}\text { NEB buffer } \\
2(\mu \mathrm{L})\end{array}$ & $\begin{array}{l}5 \mathrm{mM} \\
\mathrm{dNTPs}(\mu \mathrm{L})\end{array}$ & $\begin{array}{l}\mathrm{H}_{2} \mathrm{O} \\
(\mu \mathrm{L})\end{array}$ & $\begin{array}{l}\text { Tailed } \\
\text { DNA }(\mu \mathrm{L})\end{array}$ & $\begin{array}{l}\text { Klenow } \\
(\mu \mathrm{L})\end{array}$ & $\begin{array}{l}\text { Total } \\
\text { volume }(\mu \mathrm{L})\end{array}$ \\
\hline$>75$ & $0.60(25 \mu \mathrm{M})$ & 5.0 & 2.0 & 20.4 & 20.0 & 2.0 & 50 \\
$50-75$ & $0.30(25 \mu \mathrm{M})$ & 2.5 & 1.0 & 0.20 & 20.0 & 1.0 & 25 \\
25 & $0.15(25 \mu \mathrm{M})$ & 2.5 & 1.0 & 0.35 & 20.0 & 1.0 & 25 \\
$10^{\mathrm{b}}$ & $1.50(1 \mu \mathrm{M})$ & 1.0 & 0.4 & 0.20 & $6.5^{\mathrm{b}}$ & 0.4 & 10 \\
$5^{\mathrm{b}}$ & $0.75(1 \mu \mathrm{M})$ & 1.0 & 0.4 & 0.95 & $6.5^{\mathrm{b}}$ & 0.4 & 10 \\
$2.5^{\mathrm{b}}$ & $0.38(1 \mu \mathrm{M})$ & 1.0 & 0.4 & 1.32 & $6.5^{\mathrm{b}}$ & 0.4 & 10
\end{tabular}

aUsing limiting amounts of primer is highly advisable when amplifying from very small amounts of starting material. Not only will this decrease the amount of primer-dimer product (see the Troubleshooting section of Whole Genome Amplification by T7-based Linear Amplification of DNA (TLAD): III. Sample Purification [Liu et al. 2008c]), but it may also increase the yield of the desired amplification product. The table gives the single reaction volumes to use for a suggested mass range of starting material.

${ }^{\mathrm{b}}$ The tailed DNA will need to be dried down in a vacuum centrifuge to the volume indicated for reaction volumes that total $10 \mu \mathrm{L}$.

2. Incubate the reaction in the thermal cycler using the following program:

\begin{tabular}{ll} 
Temperature & Time \\
\hline $94^{\circ} \mathrm{C}$ & $2 \mathrm{~min}$ \\
Ramp to $35^{\circ} \mathrm{C}$ & $-1^{\circ} \mathrm{C} / \mathrm{seC}$ \\
$35^{\circ} \mathrm{C}$ & $2 \mathrm{~min}$ \\
Ramp to $25^{\circ} \mathrm{C}$ & $-0.5^{\circ} \mathrm{C} / \mathrm{sec}$ \\
$25^{\circ} \mathrm{C}$ & $45 \mathrm{sec}$ (up to $5 \mathrm{~min}$ )
\end{tabular}

A pause of up to $5 \mathrm{~min}$ at $25^{\circ} \mathrm{C}$ is permitted if time is needed for adding Klenow to a large number of samples.

3. Remove the tubes and add the amount of Klenow DNA polymerase indicated in Table 1 ( $1 \mu \mathrm{L}$ for a $25-\mu \mathrm{L}$ reaction volume). Centrifuge the tubes briefly and return them to the cycler. Incubate at $37^{\circ} \mathrm{C}$ for $90 \mathrm{~min}$ to fill in the second strand.

4. Stop the reaction by adding $0.5 \mathrm{M}$ EDTA ( $\mathrm{pH} 8.0$ ) to $50 \mathrm{mM}$ final concentration ( $2.5 \mu \mathrm{L}$ for a 25 $\mu \mathrm{L}$ reaction volume).

\section{Sample Purification using MinElute Columns}

This method is based on the MinElute Reaction Cleanup kit protocol provided in the MinElute Handbook (supplied with the kit), except that the elution volume has been doubled from $10 \mu \mathrm{L}$ to $20 \mu \mathrm{L}$ because of the small amounts of DNA being purified at each step. Without this increase in elution volume, yields may drop by as much as 50\% (possibly because the MinElute columns have a decreased recovery yield for nanogram quantities of DNA).

5. Add Buffer ERC to each sample, according to sample volume:

i. In a sample of volume 20-100 $\mu \mathrm{L}$, add $300 \mu \mathrm{L}$ of Buffer ERC and mix thoroughly.

ii. If the sample is in $<20 \mu \mathrm{L}$, make it up to $20 \mu \mathrm{L}$ with nuclease-free $\mathrm{H}_{2} \mathrm{O}$ and proceed as described in Step 5.i.

iii. If the sample is in $>100 \mu \mathrm{L}$, split the sample into aliquots $<100 \mu \mathrm{L}$, and process each aliquot in its own column as described in Step 5.i.

6. (Optional.) If the buffer color is orange or purple (i.e., $\mathrm{pH}$ greater than7.5), add $10 \mu \mathrm{L}$ of $3 \mathrm{M}$ sodium acetate ( $\mathrm{pH}$ 5.0).

If the buffer is yellow, no additional sodium acetate is needed.

7. Apply the sample mixture to the MinElute spin column (sitting in a 2-mL collection tube) and centrifuge for $1 \mathrm{~min}$ at maximum speed in a microcentrifuge.

8. Discard the flow-through, and add $750 \mu \mathrm{L}$ of Buffer PE (which must contain ethanol). Centrifuge for $1 \mathrm{~min}$ at maximum speed in a microcentrifuge. 
9. Discard the flow-through and centrifuge for $1 \mathrm{~min}$ at maximum speed in a microcentrifuge to dry the column.

10. Transfer the column to a fresh 1.5-mL nuclease-free microcentrifuge tube. Pipette $20 \mu \mathrm{L}$ (twice the manufacturer's suggested elution volume) of Buffer EB directly onto the column membrane. Let it stand for $1 \mathrm{~min}$, and then centrifuge for $1 \mathrm{~min}$ at maximum speed in the microcentrifuge to elute.

In Vitro Transcription (IVT)

11. Dry down the eluate obtained in Step 10 from $20 \mu \mathrm{L}$ to $8 \mu \mathrm{L}$ in a vacuum centrifuge for 10-12 min at medium heat.

12. Prepare the IVT reaction mixture in $0.2-\mathrm{mL}$ RNase-free tubes by combining:

$$
\begin{array}{ll}
8 \mu \mathrm{L} & 75 \mathrm{mM} \text { NTP mix } \\
2 \mu \mathrm{L} & 10 \mathrm{X} \text { reaction buffer } \\
2 \mu \mathrm{L} & \text { Enzyme mix } \\
8 \mu \mathrm{L} & \text { Template DNA from Step } 11
\end{array}
$$

If the template DNA is small $(<300 \mathrm{bp})$, it may be helpful to boost the reaction by increasing the enzyme mix to $2.4 \mu \mathrm{L}$ and decreasing the NTP mix to $7.6 \mu \mathrm{L}$. The reaction yield may increase by $10 \%-30 \%$ because of the more favorable stoichiometric ratio of enzyme to template DNA in the boosted reaction. However, since this may lower the maximum theoretical yield, this step is not recommended for larger DNA templates.

Warm reaction buffer to room temperature before addition. Addition of cold buffer to the template DNA risks precipitation of the DNA.

13. Incubate overnight at $37^{\circ} \mathrm{C}$ (acceptable range is $5-20 \mathrm{~h}$ ) in the air incubator or in a thermal cycler with a heated lid. (If using a thermal cycler that does not have a heated lid, centrifuge the tubes every 30 min during the incubation.)

\section{TROUBLESHOOTING}

Troubleshooting information (including information about generation of template-independent product during second-strand synthesis) for this protocol and the related TLAD articles in this set (Parts I and III; see Related Information) is available in the Troubleshooting section of Whole Genome Amplification by T7-Based Linear Amplification of DNA (TLAD): III. Sample Purification (Liu et al. 2008c).

\section{ACKNOWLEDGMENTS}

C.L.L. is supported by a Graduate Research Fellowship from the National Science Foundation. S.L.S. is an investigator at the Howard Hughes Medical Institute. B.E.B. is supported by a K08 Development Award from the National Cancer Institute. This work was supported by a grant from the National Institute for General Medical Sciences.

\section{REFERENCES}

Liu, C.L., Schreiber, S.L., and Bernstein, B.E. 2003. Development and validation of a T7 based linear amplification for genomic DNA. BMC Genomics 4: 19 doi: 10.1186/1471-2164-4-19.

Liu, C.L., Bernstein, B.E., and Schreiber, S.L. 2008a. Whole genome amplification by T7-based linear amplification of DNA (TLAD): Overview. CSH Protocols (this issue) doi: 10.1101/pdb.top42.

Liu, C.L., Bernstein, B.E., and Schreiber, S.L. 2008b. Whole genome amplification by T7-based linear amplification of DNA (TLAD): I. CIP treatment of samples and tailing reaction with terminal transferase. CSH Protocols (this issue) doi: 10.1101/pdb.prot5002.

Liu, C.L., Bernstein, B.E., and Schreiber, S.L. 2008c. Whole genome amplification by T7-based linear amplification of DNA (TLAD): III. Sample purification. CSH Protocols (this issue) doi: $10.1101 /$ pdb.prot5004. 


\title{
Whole Genome Amplification by T7-Based Linear Amplification of DNA (TLAD): II.
} Second-Strand Synthesis and In Vitro Transcription

\author{
Chih Long Liu, Bradley E. Bernstein and Stuart L. Schreiber
}

Cold Spring Harb Protoc; doi: 10.1101/pdb.prot5003

\begin{tabular}{cc}
\hline $\begin{array}{r}\text { Email Alerting } \\
\text { Service }\end{array}$ & Receive free email alerts when new articles cite this article - click here. \\
\hline $\begin{array}{c}\text { Subject } \\
\text { Categories }\end{array}$ & Browse articles on similar topics from Cold Spring Harbor Protocols. \\
& Bioinformatics/Genomics, general (192 articles) \\
& DNA Sequencing (96 articles) \\
& Genetic Variation (86 articles) \\
& Genetics, general (374 articles) \\
& Genome Analysis (191 articles) \\
& Genomic DNA (135 articles) \\
& Genomic Libraries (66 articles) \\
& Immunoprecipitation (75 articles) \\
& Libraries (147 articles) \\
& Libraries, general (113 articles) \\
& Molecular Biology, general (1293 articles) \\
RNA (317 articles) & RNA, general (269 articles) \\
&
\end{tabular}

